\title{
ARTICLE
}

\section{IDENTIFYING SOME FACTORS AFFECTING MEDICAL SERVICE QUALITY (Case of secondary level hospital)}

Ariunjargal N. *

Department of business administration, School of Business University of the Humanities, Ulaanbaatar, Mongolia

\begin{abstract}
In recent years public concern over health care services has been growing which signals the need for health organisations to improve the quality of their service. The Resolution 13 of the Health Minister issued on 13 January 2014 "On approving guidelines for conducting customer satisfaction surveys" endorsed a questionnaire and a sample form aimed at identifying the quality of medical service and client satisfaction. Every year, state-owned clinics carry out survey among their customers using these documents and accordingly improve on their work and performance. However, customers' assessment of the quality of services being provided by health organisations has not been able to find any improvement in health services.

Since health organisations are service providers, customers' assessment measures their quality and performance. On the other hand, researchers have identified a number of factors that affect the quality of medical care and customer satisfaction. Therefore, it is significant to optimally identify factors affecting customer satisfaction with regard to health care. Examining the perceptions of and expectations from health care service providers, including practitioners and health organisations, management has been identified as the most important need of the day.

Management will make it possible to pinpoint factors that cause poor quality of health care. Most researchers employ the SERVQUAL quality model of Parasuraman, Zeithaml and Berry (1988) Parasuraman (1985), and Zeithaml, Berry (1988) and Gronroos'(2000) indicators of service quality. The current study investigates the impact of factors that affect the quality of health services, and contains additional indicators related to measuring levels of significance of each dimension oriented to individuals that receive health care from the second tier hospitals of 6 districts in UB and health care providers respectively, plus some measurement items related to organisational issues of improving health care quality and health care system issues that have been identified by the customers themselves.
\end{abstract}

Keywords: service quality; quality measurement/indicators; quality of health care;

\section{INTRODUCTION}

Practitioners and other staff in charge of health care services are obliged to pay more attention to the demands and expectations of customers regarding the quality of their 
services. [9]. Criterion for assessing quality of health care organisation services should be measured by judgment and evaluation given by customers as important subjects of beneficiaries of these services. This would help improve the quality of the services delivered to them. A common approach in defining service quality by scientists reveal that many of them agree on its dependency on customer satisfaction (difference between their expectations and service delivery). These scientists have developed samples of measuring service quality based on their own criterion. Parasuraman, Zeithaml, and Berry first developed the samples of Servqual questionnaires for the purpose of defining and analysing the gap between customer expectations and their experience. Five-score Likert's measurement was used in their model. American scientists Parasuraman, Zeithaml, Gronroos have developed 12 indicators of measuring service quality, but the parameters of 'providing patients with clear information' and 'ability to understand the patient's needs' were not included in other scientists' models,

\section{MATERIALS AND METHODS}

Researchers have found that the quality of service depends on the satisfaction and expectations of the client and the gap in the services received. [8] In assessing the service quality clients compare their expectations and their experience. [2].

\section{Model of technical quality and service process quality (Nordic model)}

The Nordic, model first developed by the Finnish researcher, was based on service quality [3] and later promoted by other researchers. According to this model, the clients have certain perceptions and expectations from the service so they usually compare them with their experience. If their experience of service quality meets their expectations, they are satisfied with it, if it exceeds their expectations, their satisfaction level is higher, and if not, they have a lower level of satisfaction. which therefore, have been excluded from the research. The rest 10 indicators divided in 40 sub-indicators have been considered suitable for defining the service quality of secondary level hospitals.

The questionnaire consists of two main sections. In the first section the secondary level City Health Centre will identify expectations and perceptions of the three stakeholders (health service receivers, health service providers and health service policy makers) involved in the survey on health service based on 10 main indicators and 40 sub-indicators. The second section of the survey includes information on demography and other data related to stakeholders that have been collected.

1669 customers, who received health care services from the secondary level Health Centres in the capital city six districts in the period between April and June 2016 and 169 practitioners and hospital administrators have been involved in the survey. The survey has been conducted through randomized sampling and the data was analysed using SPSS 23.0 software.

According to a Finnish researcher Gronroos the expected quality is attributed to marketing elements and client's needs, but the concept of quality based on one's experience will be based on the quality of service obtained or felt in the past. [4]

\section{Servqual model to assess the service quality}

In1985, the Miami University professor Parasuraman [5] from the United States improved his method of analysing service quality by adding some measurements and called it Servqual. The first Servqual method consisted of 2 chapters, 10 indicators and 22 questions. They are:

1. Reliability. Reliability and stability of service delivery.

2. Responsiveness. It is expressed by willingness to deliver immediate 
assistance and service to clients.

3. Competence. Competence and professional skills of service providers.

4. Access. Easy to access and communicate to obtain the service.

5. Courtesy. Courtesy, friendliness and neatness of service providers.

6. Communication. Ability to provide accurate, thorough information to clients and ability to listen to them.

7. Credibility. Be sincere with customers and earn their trust.

8. Security. Care about security of service and assistance to clients, protect the staff from any risks involved and provide comfortable working conditions.

9. Understanding/knowing the customer. Make efforts in order to understand the needs of customers.

10. Tangibles. Provide the tangibles needed for service.

The Servqual model is a questionnaire used to measure the service quality of a service organisation based on a 5-score assessment by the Likert scale.

Rater model. In 1988 American researchers Leonard Berry, Valarie Zeithaml and A. Parasuraman [6] have changed the 10 indicators of measuring service quality into 5 indicators and named them the RATER model. RATER is an acronym of five factors: Reliability, Assurance, Tangibles, Empathy and Responsiveness. A Spanish scientist David Martin Consuegra (2007) has identified Servqual as the most commonly used model of measuring service quality and customer satisfaction. The abovementioned 5 measures are:

- Reliability: Reliability and trustful delivery of the promised service and professional competence.

- Assurance: Knowledge, ability to be faithful and confident.

- Tangibles: Availability of tangible objects and equipment needed in medical service.

- Empathy: Care, courtesy and willingness to help.

- Responsiveness: Delivering fast and attentive service.

- Berry, Zeithaml and Parasuraman have described the relationship between the client's expected service and the direct effects of the client's experience.

Table 1. Measures identifying service quality

\begin{tabular}{|c|c|c|c|c|c|}
\hline № & Service quality measurements & 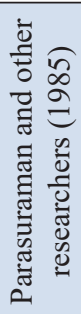 & 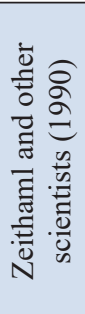 & 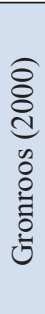 & 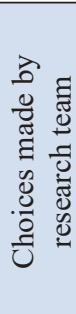 \\
\hline 1 & $\begin{array}{l}\text { Reliability of health care services provided by physicians and } \\
\text { hospital staff }\end{array}$ & $*$ & * & $*$ & $*$ \\
\hline 2 & Responsibility of physicians and hospital staff & $*$ & $*$ & $*$ & $*$ \\
\hline 3 & Assurance of physicians and hospital staff & - & $*$ & $*$ & $*$ \\
\hline 4 & $\begin{array}{l}\text { Professional skills and competence of physicians and hospi- } \\
\text { tal staff }\end{array}$ & $*$ & - & - & $*$ \\
\hline 5 & Empathy of physicians and hospital staff & $*$ & - & - & $*$ \\
\hline 6 & Credibility of health organisation & $*$ & - & $*$ & $*$ \\
\hline 7 & Patients' safety and confidentiality regarding their illness & $*$ & - & - & $*$ \\
\hline
\end{tabular}




\begin{tabular}{|c|l|c|c|c|c|}
\hline 8 & $\begin{array}{l}\text { Careful handling of patient(s) with regard to specific features } \\
\text { of his/her illness }\end{array}$ & - & $*$ & $*$ \\
\hline 9 & $\begin{array}{l}\text { The ease of communication with the patient and accessibility } \\
\text { of the health service to the patient }\end{array}$ & $*$ & - & $*$ & $*$ \\
\hline 10 & Clarity of the information to be delivered to the patient & $*$ & - & - & - \\
\hline 11 & Ability to understand the patient's needs & $*$ & - & - & - \\
\hline 12 & $\begin{array}{l}\text { The appearance and behaviour of doctors and medical pro- } \\
\text { fessionals }\end{array}$ & $*$ & $*$ & $*$ & $*$ \\
\hline
\end{tabular}

Note: (*) measurement supported by the researcher, (-)measurement not supported by the researcher

In order to identify the quality of service of the health organisations the following hypotheses were made and outcomes were developed by II level six clinics' patients, doctors, medical personnel and hospital administrators of secondary level clinics in Bayangol, Bayanzurkh, Sukhbaatar, Songinokhairkhan, Chingeltei and Khan-Uul districts of Ulaanbaatar:

- Hypothesis 1. The clients or patients are satisfied with the health care service quality.

- Hypothesis 2. There is no gap between the client expectations on prospective service quality and the actual performance quality as assessed by the clients.

- Hypothesis 3. Service quality and customer satisfaction are positively related. Hypothesis 4. There is no gap between the medical staff's assessment and customers' assessment of the quality.

Servqual model with 43 questions and 10 measurements adjusted to Mongolian context have been used to verify these 4 hypotheses.

\section{Findings}

As for the clients of the capital city's six districts optimal sampling was estimated using Sample size calculator. The client satisfaction survey was taken using the target sampling method. The optimum sample size was 1,669.

Based on the size of the population of six districts of the capital city, which counted 2,016 citizens, our estimation of the sampling size was 1,535 clients with a $10 \%$ error. The results of the survey taken from 1,669 out of 1,689 customers meet service quality standards. Sample size is $95 \%$ probability. The number of hospital doctors and management staff to be surveyd was calculated using the above method, and 68 medical managers, 111 physicians and nurses were involved in the survey.

$42 \%$ of the respondents are males, $58 \%$ -are females and majority of them have complete secondary and higher education. An equal number of retired people, government employees, students, private entity workers as well as the unemployed have been involved in the study. $69.3 \%$ of the respondents have received 1-3 health care services at the corresponding Health Unit, and the remaining $30.7 \%$ have received services with 4 and more recurrence.

\section{RESULTS AND DISCUSSION}

\section{Results of clients' impact and factor analysis}

The factor analysis of 40 sub-indicators used in the study revealed the following results: KMO (Kaiser Meyer Olkin) statistical expectation as 0.807 , factual performance -0.7631 which can be interpreted as a good indicator. (Where $\mathrm{KMO}>=0.5-$ is valid) [7]

As the result of analysis of clients' expectation and factor of understanding, the 
variation coefficient was 61.1 , Sig=.000 which is a very good indicator. (It is important when it is greater than 10). As a result of the analysis of medical personnel's expectation and perception (Kaiser Meyer Olkin) statistical expectation was 0.7055 , factual performance -0.6819 which are also very good indicators.
The significance of Bartlett's Test (Bartlett's Test) is $\mathrm{Sig}=.000$, proving that the factor analysis is important. The variation coefficient was 59.4.

These findings illustrate that the abovementioned 10 measurements can thoroughly assess the health care service quality.

Table 2. Results of factor analysis of Health Centre physicians, hospital personnel and clients

\begin{tabular}{|l|c|c|}
\hline \multirow{2}{*}{ Measurements } & Clients of Health Centres & $\begin{array}{c}\text { Health Centre physicians and } \\
\text { hospital personnel }\end{array}$ \\
\cline { 2 - 3 } & Component matrix (a) & Component matrix (a) \\
\hline Reliability & $0.75-0.82$ & $0.65-0.87$ \\
\hline Accountability & $0.77-0.82$ & $0.53-0.86$ \\
\hline Assurance & $0.73-0.84$ & $0.76-0.82$ \\
\hline Professional skills \& knowledge & $0.81-0.83$ & $0.50-0.88$ \\
\hline Empathy & $0.27-0.86$ & $0.42-0.88$ \\
\hline Credibility & $0.58-0.82$ & $0.72-0.72$ \\
\hline Confidentiality & $0.79-0.85$ & $0.71-0.85$ \\
\hline Care and attentiveness of medical staff & $0.58-0.85$ & $0.78-0.90$ \\
\hline Accessibility of medical service & $0.71-0.82$ & $0.59-0.81$ \\
\hline Tangibles & $0.75-0.84$ & $0.72-0.85$ \\
\hline
\end{tabular}

The results shown in Table 2 illustrate the outcomes of the factor analysis conducted by 40 sub-indicators among Health Centre physicians, medical personnel and patients respectively. These results reveal that medical personnel, including physicians consider that the five measurements highlighted in bold cannot define medical service quality. These are the following five measurements: 1) Physicians and medical staff of health organisation should have professional research skills $(0.496)$; 2) ability to deliver vigorous services to patients $(0.530) ; 3)$ have sufficient professional experience $(0.584) ; 4)$ willingness to listen to patients (0.418), and, 5) have enough technical resources for an easy dissemination of information (0.589). Therefore, these 5 measurements or variables have been excluded from the study.

As for clients or patients they consider that the following variables cannot be used to measure the quality of medical service. These include the following: ethical issues related to physicians and medical personnel of medical organization (0.577); ability to understand or accept patients' special demands (0.581); and, ability to treat patients in a friendly manner (0.271). For this reason these variables have been excluded from the questionnaire and 37 measurements have been retained. The survey results prove that the sub-indicators for assessing medical service quality differ in terms of the medical personnel and patients.

\section{Results of the reliability analysis}

Examining how underlying indicators represent the main indicators used in the study or analysing the internal compatibility is important. The credibility of the analysis is expressed by the alpha coefficient of the Cronbach (1951). 
Table 3. Results of the reliability analysis of variables (Cronbach alpha)

\begin{tabular}{|l|c|c|c|c|}
\hline \multirow{2}{*}{ Variables } & \multicolumn{2}{|c|}{ Patients } & \multicolumn{2}{c|}{ Medical staff } \\
\cline { 2 - 5 } & Expectation & Perception & Expectation & Perception \\
\hline Reliability & 0.846 & 0.810 & 0.684 & 0.809 \\
\hline Accountability & 0.865 & 0.814 & 0.840 & 0.735 \\
\hline Assurance & 0.839 & 0.796 & 0.779 & 0.748 \\
\hline Professional skills \& knowledge & 0.862 & 0.836 & 0.740 & 0.672 \\
\hline Empathy & 0.845 & 0.344 & 0.793 & 0.762 \\
\hline Credibility & 0.822 & 0.665 & 0.866 & 0.762 \\
\hline Confidentiality & 0.842 & 0.839 & 0.761 & 0.783 \\
\hline Care and attentiveness of medical staff & 0.812 & 0.710 & 0.807 & 0.853 \\
\hline Accessibility of medical service & 0.824 & 0.780 & 0.860 & 0.704 \\
\hline Tangibles & 0.849 & 0.811 & 0.697 & 0.795 \\
\hline
\end{tabular}

Source: Results of survey among the clients

The reliability factor of the Kronbach the sub-indicators of the variable are quite alpha coefficient of 0.684-0.865 indicates that representative. [1]

Table 4. Results of analysis of customer satisfaction index and factor significance (IPA) based on the baseline indicators

\begin{tabular}{|c|c|c|c|c|}
\hline Indicators of service quality & 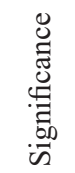 & 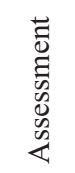 & 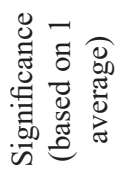 & 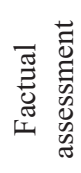 \\
\hline Reliability & 3.98 & 3.26 & 1.005 & 3.28 \\
\hline Accountability & 3.94 & 3.33 & 0.99 & 3.33 \\
\hline Assurance & 3.96 & 3.38 & 1.00 & 3.39 \\
\hline Professional skills \& knowledge & 3.92 & 3.31 & 0.99 & 3.29 \\
\hline Empathy & 3.89 & 3.26 & 0.98 & 3.20 \\
\hline Credibility & 3.94 & 3.58 & 0.99 & 3.56 \\
\hline Confidentiality & 4.01 & 3.34 & 1.013 & 3.38 \\
\hline Care and attentiveness of medical staff & 3.97 & 3.18 & 1.003 & 3.18 \\
\hline Accessibility of medical service & 4.01 & 3.24 & 1.013 & 3.28 \\
\hline Tangibles & 3.96 & 3.34 & 1.00 & 3.34 \\
\hline Total average & 3.96 & 3.32 & - & 3.32 \\
\hline
\end{tabular}

Source: Results of customer satisfaction analysis

The study results reveal that only two indicators, including confidentiality (4.01) and accessibility of medical service (4.01) show higher scores than satisfactory. However, lack of satisfactory scores in the Factual assessment column illustrates the average level of customer satisfaction.
There is a lack of indicator showing higher than average level of satisfaction among 37 sub-indicators measuring client satisfaction. All 37 sub-indicators to identify health care service quality by clients received lower than average scores. 
Two indicators of having a good reputation (3.63), being trustful, and fair (3.73) show scores higher than 3.5. These scores reveal that customer satisfaction is lower than expected. In addition, there is no positive indication of the difference between the reality and client expectations. The level of gap (-0.14-(-0.93) illustrates that factual performance is far from the reality.

Table 5. Results of analysis on factors affecting service quality

\begin{tabular}{|c|c|c|c|}
\hline \multirow{2}{*}{\multicolumn{2}{|c|}{ Indicators of Reliability }} & \multicolumn{2}{|c|}{ Component Matrix (a) } \\
\hline & & \multirow{2}{*}{$\begin{array}{c}1 \\
0.750\end{array}$} & \multirow[b]{2}{*}{0.653} \\
\hline A1 & Providing service in a mannerly way and proper order & & \\
\hline A2 & Providing service upon customer's demand & 0.820 & 0.870 \\
\hline A3 & Sincerity of the personnel in solving patient's problem & 0.811 & 0.857 \\
\hline A4 & Providing designated service on time & 0.812 & 0.807 \\
\hline \multirow{2}{*}{\multicolumn{2}{|c|}{ Indicators of Accountability }} & \multicolumn{2}{|c|}{ Component Matrix (a) } \\
\hline & & 1 & \\
\hline A1 & Responsible employee able to help & 0.769 & 0.768 \\
\hline A2 & Providing urgent and designated service when needed & 0.824 & 0.855 \\
\hline A3 & Conducting evaluation on time & 0.811 & 0.843 \\
\hline A4 & Provision of dynamic service & 0.800 & $\mathbf{0 . 5 3 0}$ \\
\hline \multirow{2}{*}{\multicolumn{2}{|c|}{ Assurance of service }} & \multicolumn{2}{|c|}{ Component Matrix (a) } \\
\hline & & 1 & \\
\hline A1 & Consistency \& courtesy in medical service & 0.730 & 0.627 \\
\hline A2 & Ability of medical staff to earn patients' trust & 0.817 & 0.819 \\
\hline A3 & Skillful physicians and medical personnel & 0.840 & 0.823 \\
\hline A4 & High professional competence & 0.763 & 0.757 \\
\hline \multirow{2}{*}{\multicolumn{2}{|c|}{ Indicators of Professional skills \& knowledge }} & \multicolumn{2}{|c|}{ Component Matrix (a) } \\
\hline & & 1 & \\
\hline A1 & Sufficient professional experience of physicians and medical staff & 0.812 & 0.584 \\
\hline $\mathrm{A} 2$ & Physicians and the medical personnel's ability to deal with issues & 0.828 & 0.868 \\
\hline A3 & $\begin{array}{l}\text { Doctors and medical personnel's knowledge and skills necessary to } \\
\text { manage the services }\end{array}$ & 0.812 & 0.875 \\
\hline A4 & Having sufficient capability for conducting professional research & 0.824 & 0.496 \\
\hline \multirow{2}{*}{\multicolumn{2}{|c|}{ Indicators of Empathy }} & \multicolumn{2}{|c|}{ Component Matrix (a) } \\
\hline & & 1 & \\
\hline A1 & Willingness of medical staff to listen to patients' requests & 0.803 & 0.418 \\
\hline A2 & Friendly attitude of medical staff & 0.855 & 0.875 \\
\hline A3 & $\begin{array}{l}\text { Warm-hearted tone of medical staff in communicating with the } \\
\text { patient(s) }\end{array}$ & 0.271 & 0.855 \\
\hline A4 & Being nice and grateful when patients leave the hospital & 0.747 & 0.844 \\
\hline \multirow{2}{*}{\multicolumn{2}{|c|}{ Credibility Indicators }} & \multicolumn{2}{|c|}{ Component Matrix (a) } \\
\hline & & 1 & \\
\hline
\end{tabular}




\begin{tabular}{|c|c|c|c|}
\hline A1 & Having prestige & 0.815 & 0.739 \\
\hline $\mathrm{A} 2$ & Being trustworthy and faithful & 0.797 & 0.824 \\
\hline A3 & Keeping confidentiality of information & 0.776 & 0.720 \\
\hline A4 & Being ethical & $\mathbf{0 . 5 7 7}$ & 0.773 \\
\hline \multirow{2}{*}{\multicolumn{2}{|c|}{ Level of observing confidentiality of information }} & \multicolumn{2}{|c|}{ Component Matrix (a) } \\
\hline & & 1 & \\
\hline A1 & $\begin{array}{l}\text { Non-disclosure of the patients' personal details (phone number, e-mail } \\
\text { address, ID number) }\end{array}$ & 0.793 & 0.707 \\
\hline $\mathrm{A} 2$ & Non-disclosure of information related to patient's illness history & 0.845 & 0.850 \\
\hline A3 & $\begin{array}{l}\text { Observing safety rules when examining the patient (for example, us- } \\
\text { ing single-use needles) }\end{array}$ & 0.844 & 0.843 \\
\hline A4 & Ethics of medical personnel & 0.801 & 0.708 \\
\hline \multirow{2}{*}{\multicolumn{2}{|c|}{ Care and attentiveness of medical staff }} & \multicolumn{2}{|c|}{ Component Matrix (a) } \\
\hline & & 1 & \\
\hline A1 & Understanding special needs of patient (client) & $\mathbf{0 . 5 8 1}$ & 0.779 \\
\hline $\mathrm{A} 2$ & Sincere attitude towards patients & 0.741 & 0.838 \\
\hline A3 & Individual care of patients & 0.849 & 0.903 \\
\hline A4 & Being accepted by clients/patients & 0.803 & 0.813 \\
\hline \multirow{2}{*}{\multicolumn{2}{|c|}{ Indicators of medical service accessibility }} & \multicolumn{2}{|c|}{ Component Matrix (a) } \\
\hline & & 1 & \\
\hline A1 & Being ready to help patients whenever they need it & 0.799 & 0.738 \\
\hline $\mathrm{A} 2$ & $\begin{array}{l}\text { Easy access to patients and clients (face-to-face meeting, telephone, } \\
\text { e-mail) }\end{array}$ & 0.779 & 0.808 \\
\hline A3 & Proper working hours for hospitals, doctors and medical staff & 0.820 & 0.777 \\
\hline A4 & $\begin{array}{l}\text { Availability of technical resources to simplify the spread of infor- } \\
\text { mation }\end{array}$ & 0.714 & 0.589 \\
\hline \multirow{2}{*}{\multicolumn{2}{|c|}{ Tangibles }} & \multicolumn{2}{|c|}{ Component Matrix (a) } \\
\hline & & 1 & \\
\hline A1 & Observing the dress code by physicians and medical personnel & 0.751 & 0.721 \\
\hline A2 & Permanent updates of medical equipment & 0.783 & 0.800 \\
\hline A3 & Keeping correct and orderly records and notes & 0.844 & 0.853 \\
\hline A4 & Transparency of medical equipment to patients & 0.819 & 0.781 \\
\hline
\end{tabular}

As a result of the analysis, it has been concluded that the quality of service can be determined by the 10 indicators and 32 subindicators based on common attitude of the 3 stakeholders.

Discussion: The present study has several limitations and the biggest of them is the choice of the hospital(s). Because of the time pressure and limited resources, our study was restricted to only six health centre clients in the capital city of Ulaanbaatar. Therefore, some other regions have been eliminated from the study. The survey respondents differ in their education level, occupation, career and the cause of getting medical service. This enabled to cover a whole range of issues related to service quality evaluation. 


\section{CONCLUSIONS}

1. Servqual model and GAP model have been accepted and used worldwide as standard models for assessing service quality and quality management.

2. The health sector is implementing two mechanisms based on quality assurance of nationwide quality management and quality improvement, and uses the international Cope model to assess the quality of services.

3. In assessing the service quality of the secondary level hospitals we consider that it is expedient to conduct it by assessing the gap between the customer expectation and actual performance of medical facilities based on 10 indicators and 32 sub-indicators. The 10 main indicators measuring customer satisfaction include the following:

- Reliability

- Accountability

- Assurance

- Professional skills and knowledge of medical staff

- Empathy

- Credibility

- Confidentiality of patient information

- Care \& Attentiveness of the medical staff

- Accessibility of medical services

- Tangibles

Based on our findings we have made the following hypothesis:

4. Hypothesis 1. The outcome of the study on customer satisfaction evaluation of health service quality shows 3.32 scores. If the evaluation level is 4.5 and more, service quality is satisfactory or is considered as good. Therefore, hypothesis ONE has not been proved.
5. Hypothesis 2. It had been assumed that there is no gap between the client expectations on prospective service quality and the actual performance quality as evaluated by the clients. However, the survey results showed that the quality of health services $(-0.64)$ or the quality of healthcare services on the part of clients has not reached the expectation level. Therefore, hypothesis TWO also cannot be confirmed.

6. Hypothesis 3. Service quality and customer's satisfaction are positively related. The result of the survey on the relation of the quality of health services and customer satisfaction showed average score (R square $=0.42$ ). Therefore, hypothesis THREE has been confirmed.

7. Hypothesis 4. There is no gap between the medical staff's evaluation and customers' evaluation of the service quality. 32 indicators can be used to identify the health care service quality by carrying out factor analysis of 10 indicators and 32 sub-indicators. The responses for 8 measures of the quality of health care services given by all respondents including clients, physicians and management do not overlap with one another, or there was little gap between their evaluation. Therefore, hypothesis FOUR has not been confirmed.

8. The clients or patients involved in the survey responded to 10 measurements and 37 sub-measurements or indicators related to customer satisfaction by health care services. The findings reveal $(-0.64)$ a gap between their expectation and actual performance of the health organisation and its personnel. In other words, health care service quality showed low results. 


\section{REFERENCES}

[1] Cortina, J. M., (1993). "What is Coefficient Alpha? An Examination of Theory and Applications". Journal of Applied Psychology. 78:98-104.doi:10.1037/0021-9010.78.1.98.

[2] Gronroos, C., (1983). A Service Quality Model and its Marketing Implications. European Journal of Marketing, 73(4), pp. 36-44.

[3] Gronroos. C., "Strategic (1982). Management and Marketing in the Service Sector", Finland Swedish School of Economics and Business Administration.

[4] Gronroos, C., (1984), A Service Quality Model and its Marketing Implications, European Journal of Marketing, vol. 18, no. 4, pp. 36-44.

[5] Parasuraman, A., Zeithaml, V. A., \& Berry, L. L., (1985). A Conceptual Model of Service Quality and its Implications for Future Research. Journal of Marketing, 49, pp. 41-50.

[6] Parasuraman, A., Zeithaml, V. A., \& Berry, L. L., (1988). SERVQUAL: A Multiple Item Scale for Measuring Customer Perceptions of Service Quality. Journal of Retailing, 64, PP. 12-40.

[7] Rajka Presbury. 2009. "Service quality in Sydney Hotels" International Journal of Hospitality Management. 22,2: p. 77.

[8] The Journal of American Academy of Business, Cambridge. Vol.8.2. March. 2006. P. 302.

[9] A. Damdinsüren. (2010) "The Health System, its Quality and Reform." 